INTERNATIONAL DESIGN CONFERENCE - DESIGN 2018

https://doi.org/10.21278/idc.2018.0438

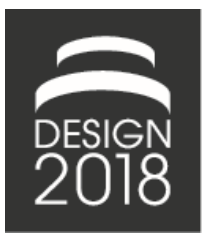

\title{
PERSONAS FOR POLICY-MAKING AND HEALTHCARE DESIGN
}

A. Gonzalez de Heredia, J. Goodman-Deane, S. Waller, P. J. Clarkson, D. Justel, I. Iriarte and J. Hernández

\begin{abstract}
Personas are widely used in design, and have recently spread to other fields such as policy-making and healthcare, where they help to convey the complexities of an ageing population. Policies and healthcare systems should rely on quantitative data to ensure the best impact on society, but no database exists that represents the aging population in a holistic and deep way, making it difficult to create effective personas. In this paper, we review the available surveys on the effects of aging, and propose three approaches that use these surveys to create better quantitative personas.
\end{abstract}

Keywords: personas, healthcare design, inclusive design, data driven design, aging

\section{Introduction}

Population aging is a serious issue that poses problems for the sustainability of current social policies and healthcare systems. New products and services need to be designed to cope with the demands of an increasingly frail section of the population. The World Health Organization in its Report about Aging and Health (WHO, 2016) highlighted the urgent need to evolve from a model centred on curing acute problems to holistic and integrated care of chronic patients. It seeks to reorient health systems so they better meet the needs of older people.

In order to address these challenges, design tools such as personas are increasingly widely used by policy-making professionals to create more people-centric policies and services. For example, the UK government have created an Open Policy Making toolkit that includes a brief description of personas (Policy Lab, 2013; Cabinet Office, 2016). Another example is the Australian Center for Social Innovation (TACSI) which uses profiles of people (similar to personas) to describe the Baby Boomers that are now reaching retirement age (Burkett and Jones, 2016).

The private healthcare sector has also started using design tools to improve the patient experience. Patient experience can be defined as "the sum of all interactions, shaped by an organization's culture, that influence patient perceptions, across the continuum of care" (Wolf et al., 2014). The power of personas for healthcare is explicitly described by other authors from the field of healthcare marketing (Leroy, 2016; Piperno, 2016). They consider that it allows the brand and design team to focus their efforts and resources on solutions that will target the right customers, keeping their needs central as the organisation moves closer to products and services. This ensures a seamless experience for customers, who will enjoy improved simplicity, functionality, and usability as a result.

Personas have great potential to be valuable in policy-making and healthcare design. They can help policymakers and designers to understand the complexities of an aging population, and increase their empathy with users. The value of evidence-based personas in this context has been described by various authors. For example, Jones (2013) explains that personas can holistically capture the lived experiences of 
people, across a range of issues. This is particularly important in healthcare because a wide variety of issues, including life situations and emotional issues, affect people's ability to engage with care services. Thus personas are an appropriate contribution to "a care-centred design orientation, that can span the different needs of patient, professional and service, and help us define priorities for intervention and redesign" (Jones, 2013). Furthermore, healthcare involves a wide variety of users which can complicate the design process. In this context, personas can help to guide design and policy-making, and inform architects as to the needs and goals of users (Maness et al., 2008). They serve as lively summarizations of user groups, inform design, and inspire problem analysis activities with stakeholders (van Velsen et al., 2012) However, personas have been criticized for their lack of reliability in decision-making (Tu et al., 2010). To be reliable, they need to be based on accurate and up-to-date data about the population. However, to be useful, they also need to convey the multiple types of information that affect aging and impact policy and healthcare. These include not only medical information but also social, psychological and functional data. As design thinking and HCD practice find their way into processes that aim to cater for patient experience in healthcare there is a growing need to customize methods and techniques originally devised for more traditional applications and domains (Bate and Robert, 2007).

In this paper, we consider how to create personas that are both accurate and holistic. In Section 2 we describe different models of quantitative personas that have been used in the past to describe older or disabled people. Section 3 reviews the available surveys on disability and aging, comparing the variables used in each. Finally, in Section 4 we propose and discuss three different approaches to build on these surveys to create quantitative personas that are more reliable and holistic.

\section{Review of personas describing aging}

Personas were proposed by Cooper (1999) as a way of helping designers to empathise with users and understand their goals when using a product. They were fictional descriptions of people, each representing a key group of users and their needs and goals. Cooper's original proposal involved using qualitative methods to create the personas. However, in recent publications, several authors have proposed basing personas on quantitative data using statistical techniques (Pruitt and Grudin, 2003; Adler, 2005; Watanabe et al., 2017). These quantitative approaches are always combined with qualitative information to maintain the sense of realism and to create engagement and empathy.

Five sets of personas that consider aging are presented below. Two of them use a qualitative approach (Tive, 2016; Gonzalez de Heredia et al., 2017) and the other three also use quantitative data (Marshall et al., 2002; Reeder et al., 2011; Wöckl et al., 2012).

\section{Elderpersonas (Gonzalez de Heredia et al., 2017)}

Elderpersonas are a set of personas that aim to convey the diversity among older people through an analysis of the multidimensional aging process. They cover six different kinds of ages: chronological, biological, functional, psychological, subjective and social age (Cavanaugh and Blanchard-Fields, 2014). As a proof of concept, 36 people were interviewed and the data used create three personas corresponding to successful, normal and pathological aging (Fernández-Ballesteros, 1998). However, these Elderpersonas lack both quantitative data and detail when describing functional age.

\section{Australian Baby Boomers (Burkett and Jones, 2016)}

The Australian Centre for Social Innovation published a report of their project Innovating Age in which they described aging as a systemic event, in which the nature of aging is determined by groups of people and by society as a whole, not by individual characteristics. The information contained in each of their four descriptions of people are: family, housing, income, social network, vulnerability factors, major life events and resilience factors. This model also lacks quantitative data and detail about disabilities.

\section{Basic Senior Personas (Wöckl et al., 2012)}

The project CURE-elderly-Personas presents 30 basic senior personas that describe the diversity among elderly people from eight European countries. The personas were constructed using data from wave 1 of the Survey of Health, Ageing and Retirement in Europe (SHARE) from 2004. The personas include information related to family status, household size, social activity and contacts, economic situation, 
limitations, diseases, symptoms and general health. Wöckl et al. (2012) propose that teams using these personas add further information on goals, frustrations and behaviours specific to each project. This set of personas does not describe how many people each persona represents.

HADRIAN (Marshall et al., 2010)

This computer aided design tool includes a database of 100 real individuals including information on their anthropometry, mobility/capability, disability and coping strategies, as well as a wealth of background data. The individuals were chosen to represent diversity in the adult population. Care was taken to ensure that they cover the range of ages, body sizes and capabilities for certain types of capabilities, but they do not necessarily cover the whole range of social situations or medical conditions.

\section{Modeling the Oldest Old (Reeder et al., 2011)}

This project presents two personas based on a cluster analysis of 21 "oldest-old" people, i.e. those aged between 85 and 94. Data was gathered from these people on functional, social, spiritual, medical and cognitive variables. The personas include information on age, education, health conditions, experience with computers and social support. They also contain ratings of general health, functional status and cognition. However, the rating scales used are not very specific. For example, the cognitive status of the personas is described as "minor cognitive changes" and "moderate cognitive changes". The focus on the oldest-old and the small number of personas also limits the applicability of this work.

In summary, personas often include both quantitative and qualitative data. The quantitative data helps to identify the characteristics of different groups and the qualitative data provides an understanding of why those differences exist. Various examples of quantitative personas have been created to describe older people. However, no one example is both holistic and in-depth enough for use in many projects. Policy makers and healthcare managers need up-to-date data and in-depth understanding of people's situations and abilities in order to make new policies, products and services inclusive for everyone. The aim of this paper is to propose approaches for the creation of quantitative personas that give a holistic, deep and up-to-date understanding of the diversity existing among older people and their circumstances.

\section{Review of the available statistical data}

The currently available statistical data on older people is analysed in this section, with a view to determining if a single database exists with all the data needed to create reliable and engaging quantitative personas. Section 3.1 gives a general description of various different surveys. Section 3.2 compares the range of variables covered by each of these surveys. Finally, Section 3.3 compares the depth with which user capabilities are examined in each survey.

\subsection{General description of the surveys}

People with disabilities are a minority that has often been neglected when carrying out demographic studies. However, the aging of the population has increased the interest of authorities and governments in understanding the characteristics of this growing group of diverse people. As a result, there has been an increase in the number of national and international surveys related to disabilities and aging. Table 1 summarises the most important surveys identified for this study.

In Table 1, we focus on the UK because we consider the tools available in the UK for evaluating inclusion to be a valuable reference. We also include data from Spain to support the development of new tools locally. This work could then be scaled up to apply to other geographical locations.

It is difficult to compare disability prevalence and characteristics between countries due to the fact that disability measures and sampling methods vary from country to country (World Health Organization and World Bank, 2011). The World Health Organization have taken steps to address this with the World Health Survey, using the same questions in multiple (though not all) countries. In addition, the Washington Group has proposed tools to help countries carry out surveys in a coordinated way. These include a short and extended questionnaire on the prevalence and levels of disability in the adult population (Washington Group on Disability Statistics, 2011). In addition, they provide a tool to assess disability among children. These questionnaires are based on the International Classification of Functioning Disability and Health proposed by the World Health Organization (WHO, 2003). 
Table 1. Summary of available surveys about disability and aging

\begin{tabular}{|c|l|c|c|c|}
\hline $\mathrm{N}^{\mathrm{o}}$ & \multicolumn{1}{|c|}{ Survey } & $\begin{array}{l}\text { First } \\
\text { year }\end{array}$ & Location & Frequency \\
\hline 1 & $\begin{array}{l}\text { Washington Group Extended Question Set on } \\
\text { Functioning (Washington Group on Disability } \\
\text { Statistics, 2011) }\end{array}$ & 2011 & 60 countries & $\begin{array}{c}\text { Varies from country to } \\
\text { country }\end{array}$ \\
\hline 2 & $\begin{array}{l}\text { World Health Survey (World Health Organization, } \\
2002)\end{array}$ & 2002 & 70 countries & $\begin{array}{c}\text { Varies from country to } \\
\text { country }\end{array}$ \\
\hline 3 & $\begin{array}{l}\text { European Health Interview Survey (European } \\
\text { Commission, 2006) }\end{array}$ & 2006 & $\begin{array}{c}31 \text { European } \\
\text { countries }\end{array}$ & Every 5 years \\
\hline 4 & $\begin{array}{l}\text { English Longitudinal Study of Aging (ELSA) (Marmot } \\
\text { et al., 2002) }\end{array}$ & 2002 & England & $\begin{array}{c}\text { Every year but } \\
\text { longitudinal }\end{array}$ \\
\hline 5 & \begin{tabular}{l} 
The Disability Follow-up Survey (Grundy et al., 1999) \\
\hline 6
\end{tabular} & $\begin{array}{l}\text { Towards Better Design survey (Tenneti et al., 2012) } \\
\text { OnK }\end{array}$ & 2011 & England and \\
Wales & One-off \\
\hline 7 & $\begin{array}{l}\text { Survey on Disability, Personal Autonomy and } \\
\text { Dependency Situations 2008 (EDAD2008) (INE, 2008) }\end{array}$ & 2008 & Spain & Every 10 years \\
\hline 8 & Elderly people survey (IMSERSO, 2010; CSIC, 2010) & 2010 & Spain & 2004, 2006, 2010 \\
\hline
\end{tabular}

However, the fact that unified questionnaires have been provided does not mean that every country follows the same process to develop disability statistics. The World Health Survey (Survey 2 in the table) and the European Health Interview Survey (Survey 3) follow the ethos of the Washington Group because they integrate most of the areas proposed by this group but still they do not ask identical questions. The Disability Follow-up Survey (Survey 5) formulates its questions in a similar way, though the details of the questions differ. However, the remaining surveys are different probably due to differences in their objectives as shown in Table 2.

Table 2. Methodology used in the surveys

\begin{tabular}{|c|c|c|c|c|c|}
\hline $\mathrm{N}^{\mathrm{o}}$ & Survey & Objective & Sample & Method & $\begin{array}{l}\text { Description of } \\
\text { capabilities }\end{array}$ \\
\hline 1 & $\begin{array}{l}\text { Washington Group } \\
\text { Questions (Washington } \\
\text { Group on Disability } \\
\text { Statistics, 2011) } \\
\end{array}$ & $\begin{array}{l}\text { Conduct national and local } \\
\text { surveys, develop disability } \\
\text { specific research }\end{array}$ & $\begin{array}{l}\text { Varies } \\
\text { between } \\
\text { countries }\end{array}$ & Interview & $\begin{array}{l}\text { Difficulty level/ } \\
\text { frequency of } \\
\text { problems, } \\
\text { intensity, duration }\end{array}$ \\
\hline 2 & $\begin{array}{l}\text { World Health Survey } \\
\text { (World Health Organization, } \\
\text { 2002) }\end{array}$ & $\begin{array}{l}\text { Monitor critical health } \\
\text { outcomes and health } \\
\text { systems }\end{array}$ & 300,000 & Interview & Difficulty level \\
\hline 3 & $\begin{array}{l}\text { European Health Interview } \\
\text { Survey (European } \\
\text { Commission, 2010) } \\
\end{array}$ & $\begin{array}{l}\text { Monitor critical health } \\
\text { outcomes and health } \\
\text { systems }\end{array}$ & $\begin{array}{c}\text { Varies } \\
\text { between } \\
\text { countries }\end{array}$ & Interview & Difficulty level \\
\hline 4 & ELSA (Marmot et al., 2002) & $\begin{array}{l}\text { Examine the complex } \\
\text { relationships and causal } \\
\text { processes of aging }\end{array}$ & 10,000 & $\begin{array}{l}\text { Interview or } \\
\text { nurse } \\
\text { assessment }\end{array}$ & $\begin{array}{c}\text { Varies from } \\
\text { capability to } \\
\text { capability }\end{array}$ \\
\hline 5 & $\begin{array}{l}\text { The Disability Follow-up } \\
\text { Survey (Grundy et al., 1999) }\end{array}$ & $\begin{array}{l}\text { Help plan welfare support } \\
\text { for disabled people }\end{array}$ & 7,200 & $\begin{array}{c}\text { Expert } \\
\text { assessment }\end{array}$ & Continuum \\
\hline 6 & $\begin{array}{l}\text { Towards Better Design } \\
\text { survey (Tenneti et al., 2012) }\end{array}$ & Inform inclusive design & 362 & $\begin{array}{c}\text { Interview }+ \\
\text { tests }\end{array}$ & Test results \\
\hline 7 & EDAD2008 (INE, 2008) & $\begin{array}{l}\text { Inform the National System } \\
\text { of Dependency }\end{array}$ & 22,795 & Interview & Difficulty level \\
\hline 8 & $\begin{array}{l}\text { Elderly people survey } \\
\text { (IMSERSO, 2010; CSIC, } \\
2010 \text { ) }\end{array}$ & $\begin{array}{l}\text { Inform the National } \\
\text { Institute of Elderly People }\end{array}$ & 2,535 & Interview & $\begin{array}{l}\text { Yes or no } \\
\text { questions }\end{array}$ \\
\hline
\end{tabular}


In terms of frequency, not all surveys are conducted on a regular basis. Some are one-offs, others are conducted occasionally, while others are conducted every five years or every year. For personas to be of maximum use in policy making, they need to be kept up-to-date with the latest data. So, ideally, they should be based on surveys that are conducted regularly.

\subsection{Range of variables covered by each survey}

As described above, there is no single survey that covers all the dimensions involved in aging. Multiple aspects of aging must be considered in order to have a holistic vision of the aging process. The tool Elderpersonas (Gonzalez de Heredia et al., 2017) proposed describing aging using the six kinds of ages presented by Cavanaugh et al. (2002): chronological, biological, functional, psychological, subjective and social age. Table 3 shows which of these each survey covers.

In general, there are two kinds of surveys: one focuses on the prevalence and characteristics of disabilities (surveys 1, 2, 3, 5, 6 and 7) and the other focuses on the wellbeing and circumstances of elderly people (surveys 4 and 8). Many of the first group (surveys 1,2,3,5) describe similar variables using similar scales. In addition, the EDAD 2008 survey from Spain (Survey 7) seems to use similar criteria and shares multiple questions with the other surveys, but also includes variables related to daily life, interaction, relationships and health issues. In contrast, the English Longitudinal Study of Aging (Survey 4) and the Elderly People Survey (Survey 8) focus more on social wellbeing, economic circumstances, family support, participation in society and level of education. Finally, the only survey designed specifically to inform inclusive design is the Towards Better Design survey (Survey 6). It uses more specific measures to describe the capabilities needed to interact with everyday products. These different approaches can be identified in the table by the kind of variables that each survey covers or partially covers. If all these types of variables are to be described in a quantitative way, data from different datasets should be combined.

Table 3. Types of variables included in each survey, $Y=$ inclusion, $P=$ partial inclusion

\begin{tabular}{|c|c|c|c|c|c|c|c|c|}
\hline $\mathrm{N}^{\mathrm{o}}$ & Survey name & Range of variables & 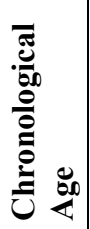 & $\frac{\sum_{0}^{\infty}}{\frac{5}{00}}$ & 预 & 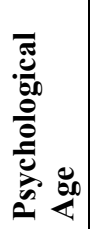 & 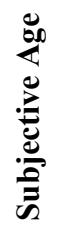 & 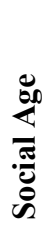 \\
\hline 1 & $\begin{array}{l}\text { Washington Group Questions } \\
\text { (Washington Group on } \\
\text { Disability Statistics, 2011) }\end{array}$ & $\begin{array}{l}\text { Disabilities, self-care, affect, pain } \\
\text { and fatigue }\end{array}$ & $\mathrm{Y}$ & & $\mathrm{Y}$ & & & \\
\hline 2 & $\begin{array}{l}\text { World Health Survey (World } \\
\text { Health Organization, 2002) }\end{array}$ & $\begin{array}{l}\text { Disabilities, self-care, affect, pain, } \\
\text { fatigue and health }\end{array}$ & $\mathrm{Y}$ & $\mathrm{Y}$ & $\mathrm{Y}$ & & & \\
\hline 3 & $\begin{array}{l}\text { European Health Interview } \\
\text { Survey (European } \\
\text { Commission, 2010) }\end{array}$ & $\begin{array}{l}\text { Disabilities, self-care, affect, pain } \\
\text { and health }\end{array}$ & $\bar{Y}$ & $\bar{Y}$ & $\bar{Y}$ & & & \\
\hline 4 & ELSA (2002) & $\begin{array}{l}\text { Functioning, health, social wellbeing } \\
\text { and economic circumstances }\end{array}$ & $\mathrm{Y}$ & $\mathrm{Y}$ & $\mathrm{P}$ & $\mathrm{Y}$ & & $\mathrm{Y}$ \\
\hline 5 & $\begin{array}{l}\text { The Disability Follow-up } \\
\text { Survey (Grundy et al., 1999) }\end{array}$ & Disabilities, use of aids & $\bar{Y}$ & & $\mathrm{Y}$ & & & $?$ \\
\hline 6 & $\begin{array}{l}\text { Towards Better Design survey } \\
\text { (Tenneti et al., 2012) }\end{array}$ & $\begin{array}{l}\text { Disabilities, psychological } \\
\text { characteristics, product use, } \\
\text { anthropometrics and demographics }\end{array}$ & $\mathrm{Y}$ & & $\mathrm{Y}$ & $\mathrm{P}$ & & \\
\hline 7 & EDAD2008 (INE, 2008) & $\begin{array}{l}\text { Disabilities, self-care, daily life, } \\
\text { interactions and relationships, health } \\
\text { issues }\end{array}$ & $\mathrm{Y}$ & $\mathrm{Y}$ & $\mathrm{Y}$ & & & $\mathrm{Y}$ \\
\hline 8 & $\begin{array}{l}\text { Elderly people survey } \\
\text { (IMSERSO, 2010) }\end{array}$ & $\begin{array}{l}\text { Family and relationships, loneliness, } \\
\text { housing, health and dependency, use } \\
\text { of time, wealth, social participation, } \\
\text { aging experience, education }\end{array}$ & $\mathrm{Y}$ & $\mathrm{P}$ & $\mathrm{P}$ & $\mathrm{Y}$ & $\mathrm{Y}$ & $\mathrm{Y}$ \\
\hline
\end{tabular}




\subsection{Comparison of the scales for describing capabilities}

Functional ability is particularly important for independent living. For example, the WHO proposes many actions to promote healthy ageing, but all have the same goal: to foster functional ability. This is done in two main ways: by building and maintaining intrinsic capacity, and by enabling those with a decrease in functional capacity to still carry out key activities (WHO, 2015).

In this section we examine how functional ability is considered in the different surveys. This is usually done by examining different kinds of user capabilities, such as vision and mobility. This differs from one survey to another. Surveys differ on the number of questions asked and the scales used to describe each capability. For example, most of the surveys ask between two and four questions about vision (surveys 1, 2, 3, 5) while EDAD2008 (Survey 7) asks 20 questions. The additional questions relate to the cause of the disability and the use of assistive technologies rather than the capability itself.

There are also differences in the scales used to measure capabilities. Most of the surveys rate capability according to the level of difficulty experienced when carrying out particular tasks (surveys 1, 2, 3, 7). Possible responses are commonly: No difficulty, Some difficulty, A lot of difficulty, and Cannot do task. However, in the Towards Better Design survey (Survey 6), standardized tests were also performed. For example, vision test charts were used to evaluate different kinds of vision capability.

Interestingly, the questions from the Disability Follow-up Survey were aggregated from levels of difficulty for individual tasks, to a continuum scale for each main capability such as vision or locomotion (Waller et al., 2010). The tasks were organized according to the impact that not being able to do them has on quality of life.

In summary, we conclude that there is no single survey that provides the holistic and detailed view required to inform policy-makers and healthcare designers. If personas are to be created that are effective for policy-making and healthcare, it may be necessary to use data from more than one dataset. However, it is unclear how this can be done in a logic and meaningful way.

\section{Methods for creating quantitative Elderpersonas}

We propose three methods that may be effective in creating holistic and detailed personas. Each may be suitable in different situations or have different concerns that need to be worked out. In considering personas, note that each set of personas and the particular choice of information included in it should be informed by the purpose for which the personas will be used.

\subsection{New survey(s)}

The most complete way to create quantitative elderpersonas is to create a new detailed survey that includes all the data needed to describe the elderly population in a holistic and detailed way. This survey would include questions from various other surveys, and would cover the following six areas:

1. Demographic data, e.g. age, sex, town size, whether they live alone or with someone else.

2. Biological age, e.g. health conditions, general health and clinical history.

3. Functional age, e.g. level of functional capabilities (related to daily activities and product use), pain and fatigue and how these affect daily activities.

4. Psychological age, e.g. energy, fatigue, levels of motivation.

5. Subjective age, e.g. whether they consider themselves old or not.

6. Social age, e.g. social network, level of support, participation in social activities.

Ideally, the survey would be conducted with a sample that was representative of the whole population in the country of interest. It is also important to determine the frequency at which the survey would be repeated in order to provide updated data to inform policy makers and healthcare managers. Dependency evaluation surveys are usually repeated every year. Coordinating with the organisations that develop these evaluations would provide one way to manage the survey more easily. After gathering the data, a technique such as cluster analysis could be used to group it into clusters that represent groups of people in the population. A persona could then be created to represent each group.

This method would create the most reliable set of quantitative personas, but would be very expensive to put into practice. Another approach is to include a short set of identical questions in more than one 
survey. These questions could cover the six key areas listed above briefly. It may be easier to add a few questions to a survey that would be conducted anyway than to conduct a whole new survey.

The resultant datasets would then be linked by having some common variables. This would provide the potential for linking data from one dataset that provides (for example) functional data with data from another dataset providing social data. This would give a more solid base for personas than using two separate unlinked surveys. However, the analysis required to do this linkage may not be straight forward.

\subsection{Layered Personas}

The second proposal is to combine information from more than one survey using layered personas (Marcengo et al. 2009). These personas consist of several layers, different combinations of which can be used in different projects. Some of the layers are developed once and reused in multiple projects, and some are developed for specific projects, taking into account the application context of individual projects. Different layers can also provide different kinds of information relevant to different situations. A similar structure could be used to present the quantitative information gathered from different sources. For example, one layer could include information on functional age from one survey, while another includes information on social age from another.

However, there are challenges over how the layers from different surveys could be combined into a coherent set of personas. One potential way to do this is to first create clusters from the different surveys separately. An example is shown in Figure 1. Clusters A1 to A3 are produced by cluster analysis on survey A, and contain information on functional age. Clusters B1 to B4 come from survey B and contain information on social age. Both sets of clusters also contain some information on demographic variables.

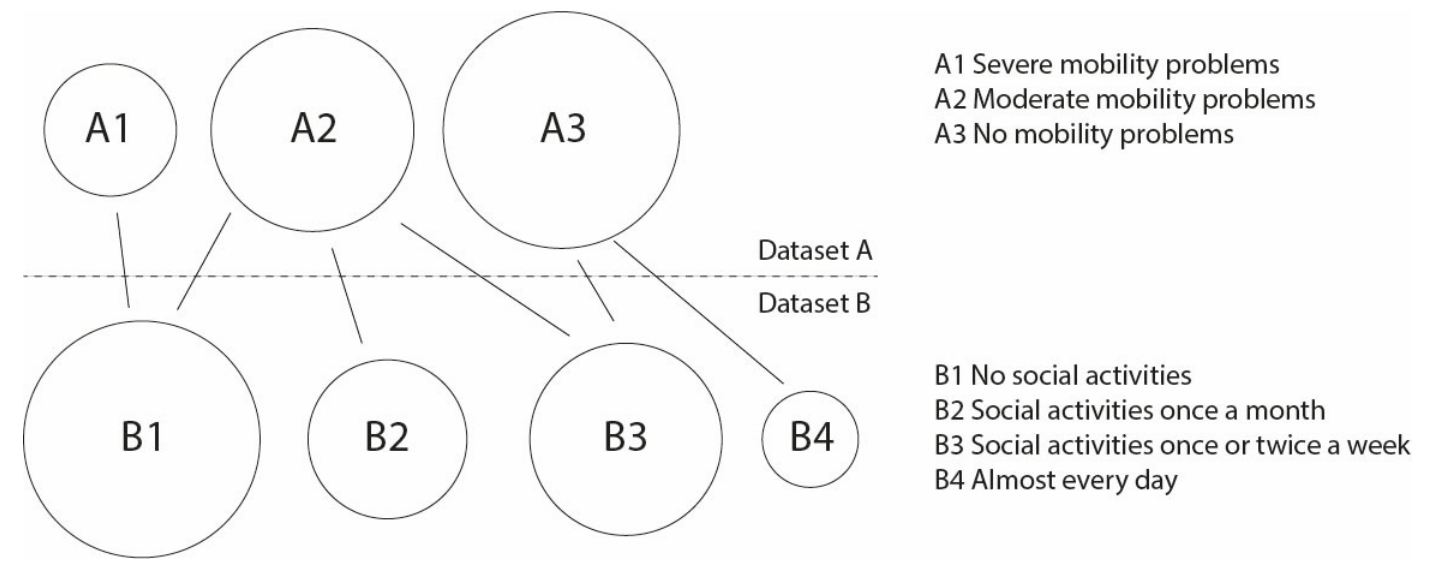

Figure 1. An example of linking between clusters in different datasets

To combine the sets of clusters, information is needed about how functional and social age are related. This could be obtained from interviews or by using a separate survey that examines both functional and social age, even if in less depth. Using linked surveys (as proposed in Section 4.1) may also help.

As an example, Table 4 shows some hypothetical results for how one aspect of functional age could be related to one aspect of social age. This could be drawn from a different survey or source than Survey A or B. It indicates that people with severe difficulty in moving about the house tend to participate less in social activities, and people with no difficulty tend to participate more. People with moderate difficulty are fairly evenly split between participation and no participation.

These relationships can be drawn on the cluster diagram as shown in Figure 1. The A1 cluster represents people with severe movement issues, corresponding to severe difficulty moving about the house. Table 5 indicates that in general these people tend not to participate in social activities (cluster B1). So a line is drawn between the two. In some cases, one cluster in the top row is joined to more than one cluster in the bottom row. Each pair of clusters is then expanded into a persona. For the example in Figure 1, personas would be created for: A1-B1, A2-B1, A2-B2, A2-B3, A3-B3 and A3-B4. 
Table 4. Example of cross-tabulation of one functional variable (difficulty moving round the house) with one social variable (participation in social activities)

\begin{tabular}{|l|c|c|}
\hline & $\begin{array}{c}\text { Participation in social } \\
\text { activities }\end{array}$ & $\begin{array}{c}\text { No participation in social } \\
\text { activities }\end{array}$ \\
\hline Severe difficulty moving around the house & $20 \%$ & $80 \%$ \\
\hline Moderate difficulty moving around the house & $60 \%$ & $40 \%$ \\
\hline No difficulty moving around the house) & $90 \%$ & $10 \%$ \\
\hline
\end{tabular}

This proposed approach is still tentative and has many challenges. When the information used for pairing the clusters is more crude than the information in the clusters themselves, it can be hard to decide on the exact pairing. This is shown in the example above, where Table 5 only provides information on whether or not there is participation in social activities, not about the level of that participation. The person creating the clusters has to use some judgement when creating the pairings. In addition, it is unclear how well the pairing would work when the clusters contain information on more than one variable. There is also a danger that this method would result in a very large number of clusters that are hard to manage. Another issue is that the pairing process makes it difficult to determine the size of the resultant clusters. One advantage of using survey data is that it provides an estimate of how large each cluster is (e.g. A1 to $\mathrm{A} 3$ and $\mathrm{B} 1$ to $\mathrm{B} 4$ in the example above). However, it is unclear how large the paired clusters are (e.g. the pair A2-B2). Further research could investigate ways to address this problem.

\subsection{Iterative personas}

Another way to use data from more than one survey is to base the personas on a small number of real people. Data can be gathered about these real people using measures from both surveys. An iterative process can be used to refine and expand this set, and ensure that it is representative of the whole population. The process is summarised in Figure 2 and described in more detail below. This description assumes two surveys (Survey 1 and Survey 2) but it may be possible to expand the process to a larger number of surveys.

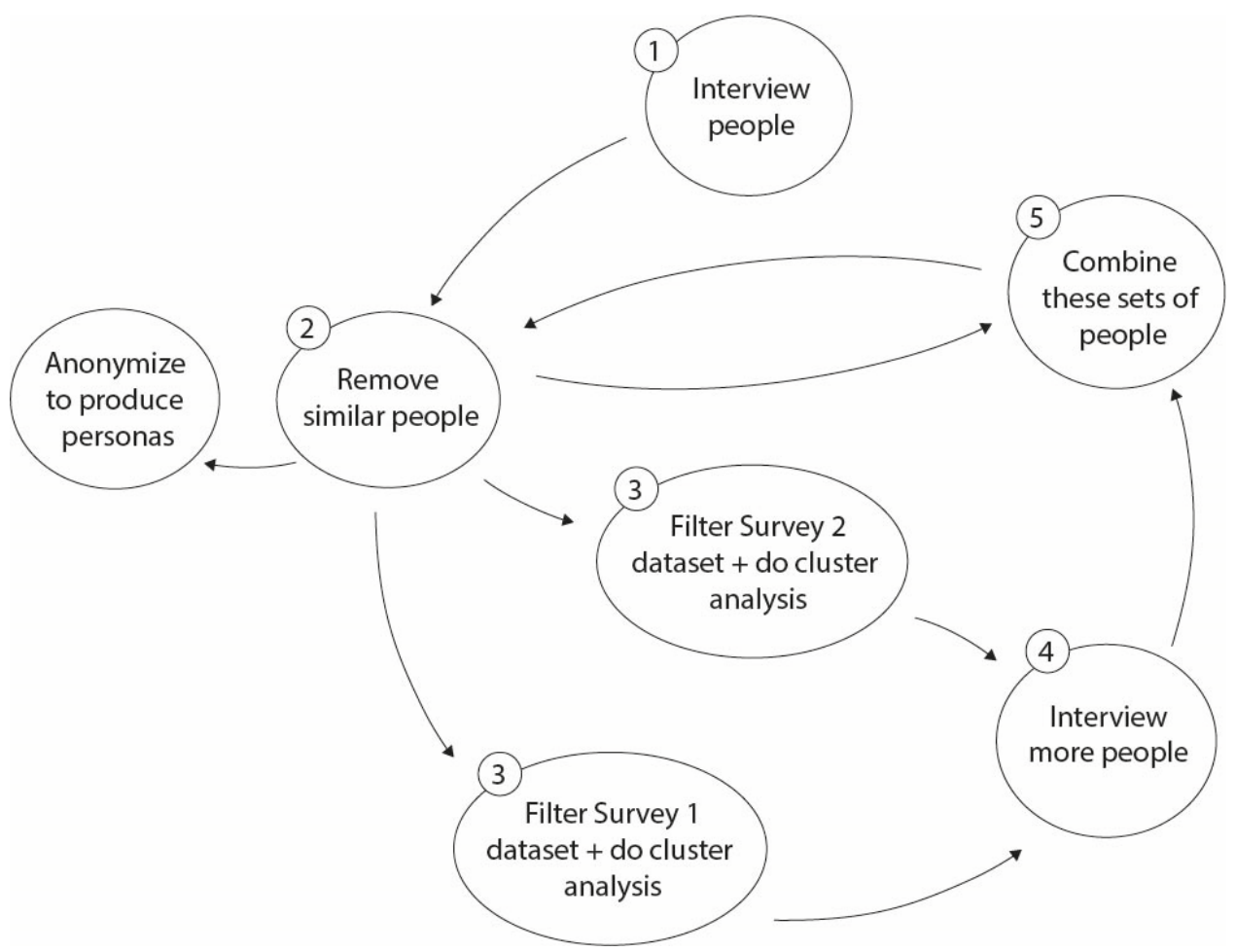

Figure 2. The development process for iterative personas 
1. Recruit some people who are relevant to the decision that needs to be made. A reasonable number of people (n) might be 10 to 20. Give them the relevant survey questions from Survey 1 and Survey 2. It may also be helpful to interview them or conduct user trials with them to get more in-depth information about them on topics of interest to the project.

2. Examine this set of $\mathrm{n}$ people and filter out people who are very similar to each other. For person $\mathrm{P} 1$ and person $\mathrm{P} 2$ to be considered similar, they should have similar results on all the measures of interest from both Survey 1 and Survey 2. The measures of interest should be chosen based on the purpose that the personas will be used for. If P1 and P2 are similar based on the measures in Survey 1 but not those in Survey 2, keep them both in. If they are similar on both measures, keep one of them and remove the other. This gives a set of $\mathrm{N}$ people.

3. Use these N people as a starting point for the persona set. Filter the Survey 1 dataset to exclude all participants who are close to one of these $\mathrm{N}$ people (based on their answers to the Survey 1 questions). Do the same for the Survey 2 dataset based on the answers to the Survey 2 questions. For each of the N people, calculate how many participants from Survey 1 are similar to that person, and how many participants from Survey 2 are similar to that person. This gives a rough indication of how many people that person represents.

Perform cluster analyses on the filtered datasets from Survey 1 and Survey 2. These will indicate the kinds of people that are currently not included in the persona set.

4. Recruit M additional people that roughly match the clusters from Survey 1 and that roughly match the clusters from Survey 2. Give all of them the (relevant) survey questions from both Survey 1 and Survey 2, and any additional interviews or user trials desired.

5. Ideally, these M people would match the centres of all the remaining clusters, but this is unrealistic in practice. Often it is hard or impossible to find exactly the right people. As a result, it is useful to iterate the process. Add the $\mathrm{M}$ additional people to the previous set of $\mathrm{N}$, then return to step 2 to check how well the new set of people covers the whole population, and recruit additional people if necessary.

In theory, as this process is repeated multiple times, the set of people interviewed will cover an increasing proportion of the total population. At some stage it will be necessary to make a judgement call as to when the set is comprehensive enough to inform the decision that needs to be made.

Note that this process produces a set of real people with rich data. An anonymization step may be required to translate these into personas that can be shared and used more publicly. For example, Jay et al. (2012) created personas from descriptions of real people, but changed contextual data that might identify them, such as specialist hobbies and occupations, and details of their children.

\section{Discussion}

Creating a new survey that covers all areas of interest (Section 4.1) would be the best approach in terms of the quality of the data. However, this would require large amounts of resources and time. In addition, in order to use public resources efficiently, coordination with different institutions that carry out similar surveys would be necessary. This coordination may be difficult due to institutions' different objectives. An alternative proposed in Section 4.1 involves adding a small set of questions to several existing surveys. This is more feasible, and would help with maintaining up-to-date data. However, there may still be difficulties in persuading and collaborating with different organisations. This method does not solve the issue entirely. Although the surveys would provide data on the whole range of variables, there would still be no survey that covers the whole range in detail. However, it would provide a useful way to link together data from different surveys, perhaps using the method suggested in Section 4.2.

Section 4.2 proposed a layered approach. It suggested creating clusters from more than one survey and then matching them based on data from interviews or surveys (such as those from Section 4.1). However, matching the clusters from different datasets could present difficulties, particularly if the clusters are based on many different variables. It may also be difficult to maintain the quantitative nature of the personas and determine how many people are represented by each combination of clusters. This depends on the data available for the matching. This proposal is still in early stages. Further work is needed to 
try it out on real datasets. Detailed statistical analysis is required to determine how effective the crosstabulation could be and whether it is possible to determine the size of cluster combinations.

The method proposed in Section 4.3 uses profiles of real people and matches them to multiple surveys based on their answers to questions from those surveys. This proposal gives a good mix of quantitative and qualitative data, and the iterative process provides a way to gradually increase the quality of the personas. It may be more difficult to implement than the proposal in Section 4.2 due to the need to interview additional people, but it is substantially easier than creating a whole new survey.

All of these methods have some potential. The third one seems particularly promising. However, all of these are early-stage proposals. Further work is needed to see how they work in practice.

To consider the feasibility of developing a proof-of-concept for iterative personas (Section 4.3), a hypothetical scenario was considered where personas would be developed to inform the provision of transport services to day care facilities. In this scenario, various types of data would be relevant, including levels of mobility (functional age), support (social age) and motivation (psychological age). As seen in Table 3, no single survey covers all of these, but EDAD2008 (Survey 7) covers functional age and social age, while IMSERSO 2010 (Survey 8) covers psychological age and social age.

Furthermore, data is available from 36 previous interviews (Gonzalez de Heredia et al., 2017) that cover all of these types of data. These interviews could be used as the starting point for the iterative process described in Section 4.3 and Figure 2. Firstly, interviewees would be filtered to remove those that are essentially duplicates, in terms of the relevant factors for providing transport services to day care facilities (step 2). Therefore, for any interviewees with similar levels of mobility and similar levels of independence, and similar levels of support and similar levels of motivation, the analyst would choose only one interviewee to keep. The data from EDAD2008 and IMSERSO2010 could then be filtered to remove survey participants who were similar to these interviewees, and perform cluster analysis on the remaining survey participants (step 3). These clusters would describe the kinds of people that are 'missing' from the current known set of interviewees, which can inform the recruitment of further interviewees (step 4). This additional data would then be combined with the previous set of interviewees (step 5), before repeating the process again from step 2. This iteration would continue until the analyst judges that the set of known interviewees is comprehensive enough to inform the intended purpose, in which case the known interviewees would be anonymised to produce the persona set.

\section{Conclusions}

We have identified an issue with using current personas in policymaking and healthcare design, due to the lack of a single database that represents the aging population in a holistic and detailed way. We have proposed three different methods to deal with this that enable the production of more effective personas. The first method involves collecting new survey data, the second matches clusters from different surveys, and the third uses a small sample of real people to link data from different surveys. All three methods have potential but all require further work to refine and test the proposals. We present this paper to the conference with the aim of generating discussion on this topic and on the proposals.

\section{Acknowledgements}

I would like to thank the Region of Gipuzkoa for funding the project INKLUGI and the Faculty of Engineering at Mondragon Unibertsitatea and Fundación ONCE for supporting this doctoral thesis. I would also like to thank the Engineering Design Department at Cambridge University for allowing me to learn from their expertise.

\section{References}

Adler, P.J. (2005), "Dealing with interviews when creating Personas: a practical approach", Proceedings of Student Interaction Design Research Conference, pp. 84-88.

Bate, P. and Robert, G. (2007), Bringing user experience to healthcare improvement: The concepts, methods and practices of experience-based design, CRC Press.

Burkett, I. and Jones, K. (2016), Starting The Innovation Age: Baby Boomers' perspectives on what it takes to age well. [online] Analysis \& Policy Observatory. Available at: http://tacsi.org.au/wp-content/uploads/2016/05/IAReport-24-5-Web.pdf (accessed 24.11.2017). 
Cabinet Office (2016), Open Policy Making toolkit - Guidance. [online] UK Government. Available at: https://www.gov.uk/guidance/open-policy-making-toolkit (accessed: 07.12.2017).

Cavanaugh, J.C. and Blanchard-Fields, F. (2014), Adult Development and Aging, Wadsworth Publishing.

Cooper, A. (1999), The Inmates Are Running the Asylum, Sams. https://doi.org/10.1007/978-3-322-99786-9_1

CSIC (2010), Encuesta sobre personas mayores IMSERSO 2010. [online] Envejecimiento en red. EN-RED. Available at: http://envejecimiento.csic.es/estadisticas/encuestas/index.html (accessed: 16.04.2018).

Fernández-Ballesteros, R. (1998), Vejez con éxito o Vejez competente: un reto para todos, Revista Española de Intervención Psico Social.

Gonzalez de Heredia, A., Justel, D., Iriarte, I. and Lasa, G. (2017), “"Elderpersonas' adapting personas to understand the real needs of elderly people", Proceedings of the 21st International Conference on Engineering Design (ICED 17) Vol 3: Product, Services and Systems Design, Vancouver, pp. 291-300.

Grundy, E. (1999), Disability in Great Britain: Results from the 1996/97 Disability Follow-Up to the Family Resources Survey, Department of Social Security, UK

Jay, C., Harper, S. and Calman, L. (2012), Personas for Lung Cancer Patients, Carers and Healthcare Professionals, developed through the Ethnographic Coding of Empirical Data, WEL - OSS Technical Report, School of Computer ScienceUniversity of Manchester. https://doi.org/10.6084/m9.figshare.684939

Jones, P. (2013), Design for Care: Innovating Healthcare Experience, Rosenfeld Media.

Leroy, M. (2016), Understanding personas for healthcare. [online] Blue L.H. Available at: https://bluelatitude.com/site/assets/files/4267/understanding_personas_for_healthcare_blue_latitude_health.pdf?utm_campaign=Understanding $\quad \overline{\text { Personas }}$ - $\quad$ April 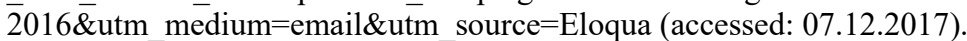

Maness, J.M., Miaskiewicz, T. and Sumner, T. (2008), "Using personas to understand the needs and goals of institutional repository users", D-Lib Magazine, Vol. 14 No. 9-10. https://doi.org/10.1045/september2008maness

Marmot, M., Banks, J., Blundell, R., Lessof, C. and Nazroo, J. (2002), English Longitudinal Study of Ageing, The Institute of Fiscal Studies, London.

Marshall, R., Case, K., Gyi, D.E., Oliver, R. and Porter, J.M. (2002), HADRIAN: An integrated design ergonomics analysis tool. [online] Available at: https://dspace.lboro.ac.uk/dspace/handle/2134/2166 (accessed: 04.06.2017).

Piperno, M. (2016), The Power of Persona Development for Health Care Marketers. [online] Marketing H.S. Available at: https://www.ama.org/publications/MarketingHealthServices/Pages/power-of-personadevelopment-for-health-care-marketers.aspx (accessed: 07.12.2017).

Policy Lab (2013), Using personas to make better policy - Policy Lab. [online] UK Government. Available at: https://openpolicy.blog.gov.uk/2013/08/08/using-personas-to-help-improve-policy-making/_ (accessed: 7.12.2017).

Pruitt, J. and Grudin, J. (2003), "Personas: practice and theory", Proceedings of the 2003 conference on Designing for user experiences - DUX '03, https://doi.org/10.1145/997078.997089

Reeder, B., Zaslavksy, O., Wilamowska, K.M., Demiris, G. and Thompson, H.J. (2011), "Modeling the oldest old: personas to design technology-based solutions for older adults", AMIA Annu Symp Proc., 2011, pp. 11661175.

Tenneti, R., Johnson, D., Goldenberg, L., Parker, R.A. and Huppert, F.A. (2012), “Towards a capabilities database to inform inclusive design: Experimental investigation of effective survey-based predictors of human-product interaction", Applied Ergonomics, Vol. $43 \quad$ No. 4, pp. $713-726$. https://doi.org/10.1016/J.APERGO.2011.11.005

van Velsen, L., van Gemert-pijnen, L., Nijland, N., Beaujean, D. and van Steenbergen, J. (2012), "Personas : The Linking Pin in Holistic Design for eHealth", Proceedings of the 4th International Conference on eHealth, Telemedicine, and Social Medicine, pp. 128-133.

Waller, S.D., Langdon, P.M. and Clarkson, P.J. (2010), "Using disability data to estimate design exclusion", Universal Access in the Information Society, Vol. 9 No. 3, pp. 195-207. https://doi.org/10.1007/s10209-0090168-x

Washington Group on Disability Statistics (2011), Washington Group - Extended Question Set on Functioning (Version 9 November 2011). [online] Washington Group on Disability Statistics. Available at: http://www.cdc.gov/nchs/washington_group.htm. (accessed: 01.12.2017).

Watanabe, Y., Washizaki, H., Honda, K., Noyori, Y., Fukazawa, Y. et al. (2017), "ID3P: Iterative Data-Driven Development of Persona Based on Quantitative Evaluation and Revision", 2017 IEEE/ACM 10th International Workshop on Cooperative and Human Aspects of Software Engineering (CHASE), IEEE, pp. 49-55. https://doi.org/10.1109/CHASE.2017.9

WHO (2003), International Classification of Funcitoning, Disability and Health. [online] World Health Organization. Available at: http://www.who.int/classifications/icf/icfchecklist.pdf (accessed: 01.12.2017). 
WHO (2016), World Report on Aging and Health, World Health Organization.

Wöckl, B., Yildizoglu, U., Buber, I., Aparicio Diaz, B., Kruijff, E. and Tscheligi, M. (2012), "Basic senior personas: a representative design tool covering the spectrum of European older adults", Proceedings of the 14th International ACM SIGACCESS Conference on Computers and Accessibility, pp. 25-32. https://doi.org/10.1145/2384916.2384922

Wolf, J.A., Niederhauser, V., Marshburn, D. and LaVela, S.L. (2014), "Defining Patient Experience Framing the Conversation on Patient Experience Defining Patient Experience", Patient Experience Journal Patient Experience Journal, Vol. 1 No. 1, pp. 7-19.

Arantxa Gonzalez de Heredia, Lecturer and researcher

Mondragon Unibertsitatea-Faculty of Engineering, Design Innovation Center (DBZ)

Loramendi 4, 20500 Arrasate-Mondragon, Spain

Email: agonzalezh@mondragon.edu 